\title{
Disturbance in Bowel Function
}

National Cancer Institute

\section{Source}

National Cancer Institute. Disturbance in Bowel Function. NCl Thesaurus. Code C5034.

Abnormal functioning of the small and/or large intestine. 